\title{
Exploring the Components of Digital literacy Curriculum: EFL and IT Instructors' Voice
}

\author{
Shadi Forutanian \\ PhD Student, University of Tehran, Iran
}

$\triangle$ Corresponding Author: Shadi Forutanian, E-mail: forutanian.shadi@ut.ac.ir

\author{
ARTICLE INFORMATION \\ Received: December 08, 2020 \\ Accepted: January 14, 2021 \\ Volume: 3 \\ Issue: 1 \\ DOI: $10.32996 /$ jeltal.2021.3.1.4
}

\section{KEYWORDS}

Digital literacy, curriculum, components, instructors

\section{ABSTRACT}

Every day we are moving toward digitalization and computerization. In education and especially online learning, we are observing fast developments. The need of a digital curriculum and digital literacy for better teaching and learning is sensible. Thus, a digital literacy curriculum is a necessary tool for teachers and students. This qualitative study explored some components of the digital literacy curriculum based on EFL and IT instructors' voice. Also, the researchers found digital tools that they used a lot and their purposes behind applying these digital tools. The results show that EFL and IT instructors had focused on production, communication, evaluation of digital skills in cyberspace. Most of them were aware of digital literacy definition and suggested some components of the digital literacy definition components and suggested designing a digital literacy curriculum. Among all digital tools, they used WhatsApp and Bigbluebutton more. Based on all retrieved data, the researchers proposed a digital literacy curriculum framework and identified the need for further study about applying this framework in real life. Doing need analysis before designing a digital literacy curriculum to know students' and teachers' digital talent and awareness is another area that further research should have done.

\section{Introduction}

Language teachers' responsibility was extended as communication around the globe became increasingly digitally mediated. Today, language learners need to activate their digital skills in order to engage in effective communication in the electronically connected world. Hague and Payton (2010) define digital literacy as follows:

Digital literacy: (a) can be developed alongside subject knowledge in all classrooms across the curriculum at both primary and secondary levels; and (b) can be important not only in supporting students to become independent, critical learners but also in narrowing the gap between students' experiences inside and outside of school (Hague \& Payton, 2010).

Ideally, the deliberation process behind the design of a digital literacy curriculum should include instructors' voice in the subject area (Levin, 2008, p. 17). Considering instructors in designing digital literacy curriculum has a significant effect on curriculum components' quality. No one except instructors can feel and see the problem of online learning and find solutions for them. For every university with a digital education plan, having a digital literacy curriculum due to increasing students and teacher's digital literacy knowledge is inevitable. If curriculum designer and researcher can plan a special digital literacy curriculum for adults (teachers, staff, and students), that will be applicable. Choosing sound and clear digital literacy curriculum components is a hard job. All theories and frameworks are good on the paper, but how about their application in real life. Did they act as a perfect tool in the context? After studying and searching many books and research papers, the clear definition for digital literacy or its curriculum never be found. Maybe the reason behind this problem is that no scholars and researcher think about this subject the same. In fact, the combination of $s$ and perspectives of scholars' different ideas and perspectives about digital literacy curriculum

K C AL-KINDI CENTER R F FOR RESEARCH AND DEVELOPMENT Your gateway to world-class research

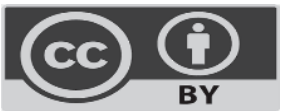

Published by Al-Kindi Center for Research and Development. Copyright (c) the author(s). This open access article is distributed under a Creative Commons Attribution (CC-BY) 4.0 license 
components and consulting Whit instructors in a related field such as IT, computational and critical thinking, ICT, and EFL open a new way for designing digital literacy curriculum and its components. This study was explored the important points about digital literacy curriculum components through an interview with EFL and IT instructors.

\subsection{Research problem}

The digital literacy curriculum not only is an important tool for teaching and learning language but also has a significant role in mixing technologies with teachers and student's life. This is necessary for online learning and distance education and should be work on the design more and more. Unfortunately, there is gap about the universal definition of digital literacy curriculum components, and EFL and IT instructors' collaborations were very low.

\subsection{Objectives of the study}

This study aims to explore digital literacy curriculum components based on EFL and IT instructors' voices to clarify the importance of digital literacy curriculum in education and help all institutions with syllabus designing in digital environments.

\subsection{Research Questions}

The researchers proposed these question base on the objects of this paper:

RQ1: What do the components of the digital literacy curriculum mean for EFL and IT instructors?

RQ2: What digital tools do these instructors use?

RQ3: For what specific purposes do these instructors use digital tools?

\section{Review of literature}

Besides a large variety in digital literacy definition, it is something beyond the just computer, ICT, information, data, media literacy. Digital literacy is somehow multiple abilities that depends on situation, context and talent. In another way, it is the usage of digital tools and technology for having a better and simpler life. Teaching and learning through digital tools and online environments make easy a lot of things, but it has its own problems. Maybe finding a universal definition for digital literacy will shed light on its unclear components. The following is the digital literacy definition by UNESCO (2018):

Digital literacy is the ability to define, access, manage, integrate, communicate, evaluate and create information safely and appropriately through digital technologies and networked devices for participation in economic and social life. It includes competences that are variously referred to as computer literacy, ICT literacy, information literacy, data literacy and media literacy.

The term literacies' plural use denotes variation in semiotic practices across time periods, contexts, communities, and cultures. The concept of multiliteracies acknowledges not only the linguistic and cultural plurality but also the increasingly multimodal expression of meaning in electronic communication. Arguments for a pedagogy of multiliteracies gained prominence in education in 1996 when The New London Group published a manifesto emphasizing a shift in meaning-making. This shift has been taking place alongside the emergence of new media in which new ways of production and consumption of texts and the establishment and maintenance of identities and relationships are observed. New digital media have altered the scale, frequency, and space of human interaction. People can now communicate with larger numbers of physically distant people more often using various forms of social media (Thorne, 2013). New media has also had implications on knowledge co-construction and collaboration, reflecting the pedagogical shift from cognitive to socio-constructivist learning theories (Thorne, 2013).

\subsection{Definition and components of digital literacy}

From a different perspective, digital literacy had been defined, but by breaking it into several parts, its components will become clear. According to Lankshear and Knobel (2008)" digital literacy is a framework that brings together many sub-literacies, skills and any attempt to constitute an umbrella definition or overarching frame of digital literacy will necessarily involve reconciling the claims of myriad concepts of digital literacy, a veritable legion of digital literacies" (p. 4).

With regard to Spires and Bartlett (2012) digital literacy practice means: (a) locating and consuming digital content, (b) creating digital content, (c) communicating digital content, (d) critical evaluation (see Figure 1). Based on this categorization, digital literacy curriculum components can be defined by extending these elements. 


\section{Locating and Consuming Digital-Content}

\section{Communicating Digital Content}

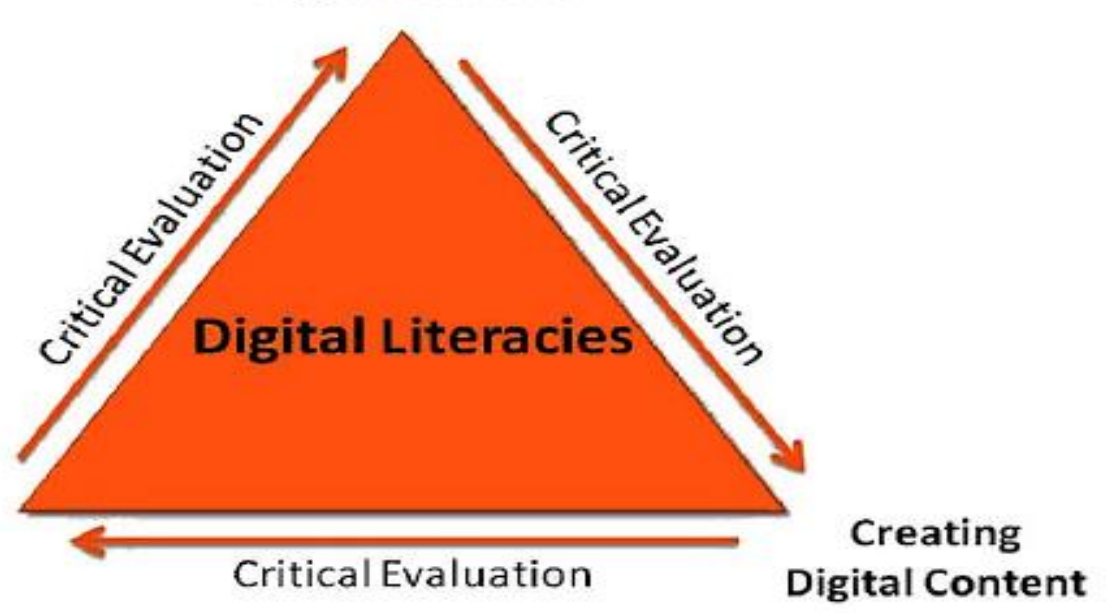

Figure 1. Digital literacy practices Spires \& Bartlett (2012)

By considering Gilster (1997) and Tang and Chaw (2016) works, digital literacy is differentiated from technological competence:

[T] o be digitally literate, one does not just know how to find information from the web, but also has the ability to understand and assemble information from different print or digital sources. Digital literacy involves the mastery of ideas and is not just about using the technology itself. (p. 56)

Also, Janssen et al. (2013) stated that "competence refers to the categorization of a discipline in a series of intertwined knowledge, skills and attitudes" (p. 474). Other definitions for digital literacy are as follow:

The capabilities which fit an individual for living, learning and working in a digital society (Jisc, 2014).

Digital literacy goes beyond functional IT skills to describe a richer set of digital behaviors, practices and identities. What it means to be digitally literate changes over time and across contexts (Jisc, 2014).

In all the above digital literacy definitions, the complex and integrated nature of it could be seen. It means that digital literacy curriculum components as digital literacy itself is made by different skills. The researchers mentioned skills because, in fact digital literacy is a set of capabilities about activity in the digital world. The researches in this study focused on exploring digital literacy curriculum components by finding a clear and complete definition of digital literacy elements through EFL and IT instructors. They applied Spires \& Bartlett (2012) digital literacy model as a backbone of their digital literacy curriculum framework.

\subsection{Digital literacy practices in language education}

In 1999, Tapscott coined the phrase Net Generation which evoked the idea that the new generation would be competent users of new technologies because they are inseparable from their digital gadgets in all aspects of their lives use of their mobile phones. Likewise, Prensky's (2001) seminal distinction between digital natives and digital immigrants suggested that digital natives, individuals who were born into the digitally connected world, would intuitively be competent users of technology. In contrast, digital immigrants had to learn how to integrate technologies into their practices to become skilful users. A decade later, White and Le Cornu (2011) challenged this distinction and proposed that the principal factor that distinguished digital skills was not age but time and effort. They, thus, suggested the terms of digital residents and digital visitors.

\subsection{Measuring digital literacy practices}

The plethora of definitions and conceptualizations of what digital literacies mean reflect on the diversity in tools that aim to measure digital literacy practices. In this survey, there are two sections - first section includes questions for the perceptions of the participants, the second section includes questions for actual practices, but it fails to go beyond measuring technical skills. 
Likewise, a report prepared by the Australian Council for Educational Research (2016) identifying criteria for developing "a global measure of digital and ICT literacy skills" suggests that due to considerable overlap between the term's digital literacy and ICT literacy, they can be used interchangeably. Similarly, Tyger (2011) develops a perceived digital literacy scale to measure teacher candidates' digital literacy, yet the scale items only ask participants' understanding of several ICT terms, such as spyware, weblog, tagging, hence focusing only on perceived ICT knowledge. Other similar instruments also use ICT competence scales (e.g., Hsu, 2010; Tondeur et al., 2017). A report written by Covello (2010) for a research project titled Analysis for Human Performance Technology Decisions demonstrates in order to emphasise ICT skills for the digital literacies measuring and the necessity to revise existing instruments regularly as technologies and learners' digital practices continue to evolve.

Given the challenges in defining digital literacies curriculum components in this paper, we explore EFL and IT instructors understanding and conceptualization of digital literacy curriculum components qualitatively, within a realistic perspective. Our aim is to identify current every day and educational digital literacy practices as well as future training needs of instructors for effective incorporation of new media platforms. The outcomes of this study are expected to guide determine of digital literacy curriculum components and the development of appropriate instruments to measure instructors' digital literacies.

\section{Methodology}

This study follows a qualitative research design. It identifies instructors' understanding of digital literacy curriculum components and explores their pedagogical use of digital tools. All participants responded to three open-ended questions via semistructured interview. The responses were analyzed qualitatively.

\subsection{Participants}

The participants of this study comprised EFL and IT instructors. A total of 40 participants (20 males, 20 females) were recruited from English language and IT faculty of the Institute of Higher Education. All information about participants mentioned in table 1.

Table 1. participants information

\begin{tabular}{|c|c|c|c|}
\hline University faculties & Total & Male & female \\
\hline IT & 20 & 10 & 10 \\
\hline EFL & 20 & 10 & 10 \\
\hline Total & 40 & 20 & 20 \\
\hline
\end{tabular}

\subsection{Instrument}

Semi-structured interview protocol was used in this study and consists of 3 open-ended questions in total as follow:

a. What do you understand from the phrase digital literacy? How you define digital literacy curriculum components? Please give details and examples.

b. What digital tools do you use? And why? Please give examples.

c. Which social media services do you use? How? For what kind of purposes do you use them (academic, personal issues, just for communication)?

\subsection{Data collection procedures}

Data were collected using open-ended questions. There were five main reasons why open-ended questions were employed. First, at the time of data collection, available scales and questions for digital literacy were mostly field-specific, and a reliable and valid scale to identify the digital literacy levels of instructors did not exist. Second, available digital literacy scales focused heavily on technical ICT skills, which were somewhat tool dependent. Third, the content of the scales predominantly included outdated tools, some no longer in use. Fourth, a qualitative approach to research design was deemed more appropriate to understand participants' voice on digital literacies curriculum components and obtain their own appraisal of their skills. Finally, due to time and pandemic situation, it was feasible to conduct individual online interviews with all the participants.

Semi-structured online interviews with all these instructors were held using open-ended questions addressed in the survey. The instructors were asked to provide more details about questions in Semi-structured online interviews. The interviews questions were based on Spires and Bartlett (2012) digital literacy model. The interviews provided the researchers with the opportunity to further explore and have an in-depth inquiry of the survey results. 


\subsection{Data analysis}

In the context of conceptualizing the collected data, the thematic content analysis method was used. Thematic content analysis is used for qualitative data, and the researchers examine data for finding repeated idea and perceptions. In the present study, instructor's idea and their awareness level about digital literacy curriculum components were determined.

\section{Results}

In this section, the researchers addressed each of the research questions and based on these results, they proposed a digital literacy curriculum framework.

\section{RQ1: What do the components of the digital literacy curriculum mean for EFL and IT instructors?}

Following qualitative analysis, five themes emerged in relation to instructors understanding of digital literacy curriculum components: (a) Digital reading and writing in cyberspace and digital networks or content production by writing in cyberspace, (b) Understanding and using digital tools, (c) communicating digital content (d) critical evaluation. See sample data for these themes in Table 2.

Table 2. Sample data for theme

\begin{tabular}{|l|l|}
\hline \multicolumn{1}{|c|}{ Theme } & \multicolumn{1}{|c|}{ Sample } \\
\hline $\begin{array}{l}\text { Digital reading and writing in cyberspace and digital } \\
\text { networks or content production by writing in } \\
\text { cyberspace }\end{array}$ & $\begin{array}{l}\text { digital literacy means reading and writing on the digital } \\
\text { era. }\end{array}$ \\
\hline Understanding and using digital tools & $\begin{array}{l}\text { I think digital literacy is understanding of digital tools } \\
\text { and using of them effectively and consciously in order } \\
\text { to live more purposefully }\end{array}$ \\
\hline Creating, sharing and collaborating & Sharing ideas for digital communications \\
\hline Critical thinking and evaluation & Applying critical thinking to evaluate \\
\hline
\end{tabular}

Their responses demonstrate that instructors were aware of digital literacy curriculum components. They believed that applying digital tools is one of the characteristics of a digitally literacy curriculum because using digital technologies effectively is an important matter for individuals.

Some instructors believed that digital literacy curriculum components are producing, understanding, evaluating data with digital tools. Other instructors focused on communication through digital tools.

In order to explore digital literacy curriculum components, instructors were asked to evaluate their own digital literacy skills. Instructor comments demonstrated different levels of self-evaluation. Some instructors were confident and had a positive appraisal of their level of digital literacy. These instructors predominantly focused on the effective contribution of technologies for themselves and for their students, as demonstrated in the following quotes:

I am digitally literate person. Because I like doing something on computer, learning about new program and using this program. (A.)

Working with digital tools are enjoyable for me and I think I'm good at this because IT is inseparable from my life. I like searching new tools, integrate them to the lessons. This makes lessons more unjoyful and attractive. (B)

On the other hand, some instructors did not consider themselves digitally literate, particularly due to a lack of interest in technologies, a preference for using more traditional means, and an inability to use digital tools effectively. Examples of these evaluations are captured in the following quotes:

I am not digitally literate person because I cannot use digital tools very effectively. I think I should promote my digital literacy because it is necessary for today digital world. (C)

I cannot say that I am digitally literate person because I am not familiar with digital tools a lot. But I know that should learn how to use them, because using digital tools is very important in our life. (D) 
These perceived data indicated that digital literacy curriculum components for instructors are about having knowledge of digital tools and the digital world. Moreover, for instructor's digital literacy curriculum, components involved the ability for using digital tools in teaching, communication and other purposes. Finally, criticality was an important aspect of digital literacy curriculum components in relation to awareness of reasons for and dangers of using digital tools. It is also important to note that this could be interpreted as some instructors were highly confident and stated that they could do whatever they wanted when they used digital tools.

However, this was mitigated by their explanation that they could do everything only with the tools they knew. As new tools are developed and implemented in teaching, appropriate training plays a key role in sustaining language teachers' confidence levels as regards their digital literacy skills.

\section{RQ2: What digital tools do these instructors use?}

The second research question in this study investigated the digital instructors used. The instructors' variety of digital tools were grouped in relation to their functions. The findings are depicted in Table 3 and Figure 2, along with the frequency of mention.

Not surprisingly, the most commonly used digital tools were social media tools, such as WhatsApp and Bigbluebutton. Almost all instructors in this study use Bigbluebutton and WhatsApp was installed as a built-in feature on all smartphones. The semistructured interviews data, revealed that almost all instructors had WhatsApp. Instructors stated that they shared, recorded, and created files and/or videos for personal and educational reasons and were conscious of what and with whom they shared their content. The second most frequently mentioned digital tools category was digital platforms, with instructors citing as Bigbluebutton. Even a small group of instructors who normally preferred Dropbox and limited participation expressed the need for Mendeley.

Despite the existence of a variety of digital platforms for professional development, the number of instructors using digital tools for professional development was low. Instructors in our study did not use these platforms and tools in order to improve their teaching and language skills. While most instructors expressed their awareness of various social media platforms and online groups in relation to their professional development, some instructors did not communicate with students from other cultures nor develop familiarity with their culture.

This could be because communication with students from other cultures is not a compulsory component in students' courses.

Table 3 Digital tools used by instructors

\begin{tabular}{|l|l|}
\hline \multicolumn{1}{|c|}{ The Digital Tools Used } & \multicolumn{1}{c|}{$\quad$} \\
\hline Drop box & $1.8 \%$ \\
\hline Google drive & $12.3 \%$ \\
\hline End note & $2.7 \%$ \\
\hline Mendely & $0.4 \%$ \\
\hline Googel meeting & $9.4 \%$ \\
\hline Skype & $12.1 \%$ \\
\hline WhatsApp & 32.6 \\
\hline Bigbluebutton & 28.6 \\
\hline
\end{tabular}




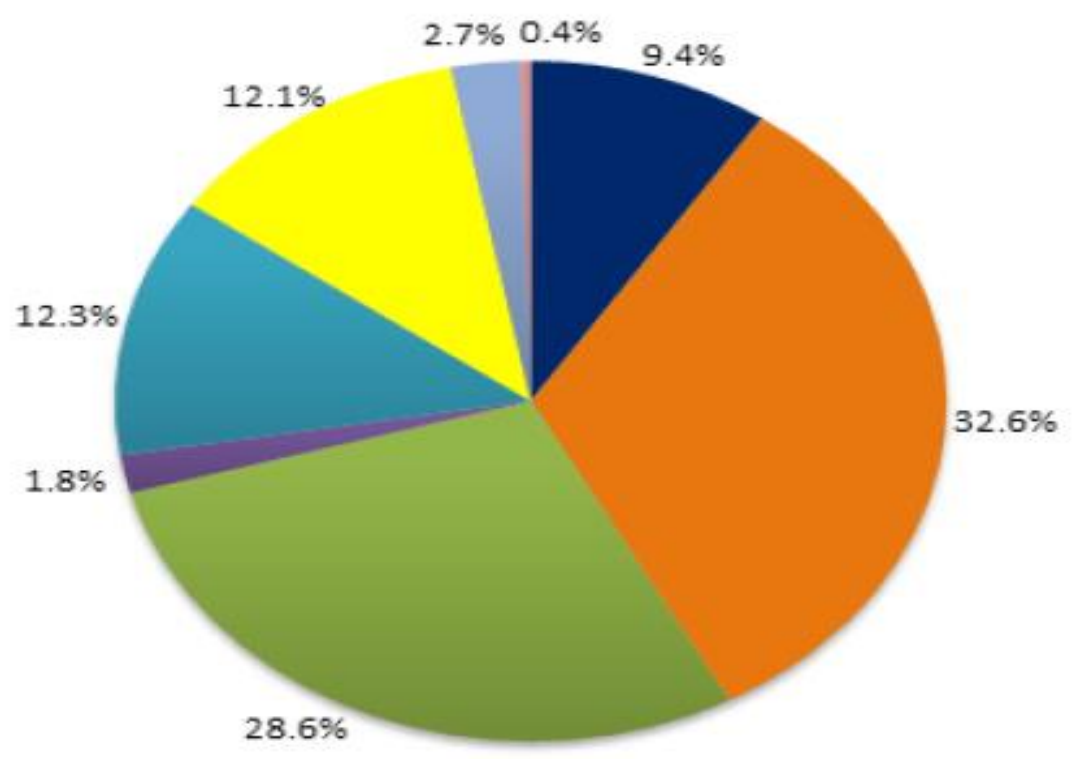

Figure 2. Frequency of digital tools used by instructors

\section{RQ3: For what specific purposes do these instructors use digital tools?}

The analysis of the semi-structured interviews also provided more information about the purposes of using digital tools. In relation to purposes for the use of digital tools to foster specific language skills instructors focused on teaching specific skills. These included the employment of a variety of digital tools to teach as well as assessment and feedback. Digital tools were also used to provide more exposure to authentic language use and to model the target culture. In terms of other pedagogical purposes, Instructors focused on improving the educational context for better teaching, for example, increasing the students' motivation or developing learner autonomy. Digital tools were also used to promote individualized learning, engagement, participation, creativity, imagination, group work, and digital design.

\section{Discussion}

This study sought to identify digital literacy curriculum components and instructors' appraisal of their digital literacy skills. According to Spires and Bartlett (2012), the digital literacy curriculum extends beyond keyboarding to making critical evaluations of digital resources and to the participants of this study, the definition of digital literacies curriculum varied.

Some instructors only focused on technical skills and being able to read and write online, whereas others demonstrated a wider understanding of digital literacy that extends beyond online reading and writing. For these participants, being digitally literate meant collaborating with others via digital tools and engaging in critical thinking. Digital literacy, using digital technology, communication tools, and networks to acquire and evaluate information, communicate with others, and perform practical tasks in Spires and Bartlett (2012) taxonomy, are among the highlighted features of digital literacy curriculum components. According to Paul Gilster (1997), digital literacy was the "ability to understand and use information in multiple formats from a wide range of sources when it is presented via computers" (p. 1). As a result, digital literacy means reading and writing in cyberspace.

In a digital literacy curriculum, these are important components. Moreover, evaluating learners before, middle, and after producing digital content is vital for maintaining accuracy and integrity. With the lack of evaluation in every step, the digital literacy curriculum's effect will be not clear. Having digital literate teachers and students all depend on a quality digital literacy curriculum.

In light of instructors' understanding of what are digital literacy curriculum components, it is possible to argue that the selfevaluation of their digital literacy skills reflected the multiple and varied definitions. Whereas some instructors only reported knowledge and use of digital tools, others reported that they could use the tools for purposeful communication with others and in their teaching. Some instructors also showed overconfidence in their skills as well as awareness of the dangers in relation to online safety. Instructors should use the technologies needs because of students' needs and because they should be prepared 
for the digital world. Based on Darling-Hammond (2010), instructors who have been in the field for some time confront the dual challenge of acquiring a disposition that accommodates ongoing change as well as 're-learning' how to teach using contemporary technologies.

Instructions about using digital literacies are vital for exploring digital literacy curriculum components. We would argue that more research is needed to construct a shared definition of digital literacies curriculum components in order to guide the teaching of such skills. Likewise, there is a need to establish a framework for the evaluation of teachers' literacy development. Also, this study amid to identify the digital tools instructors used in their personal and academic life, as well as in their initial practices. An exploration of the digital tools used by instructors indicated that they heavily used social media platforms and PowerPoint and PDF sharing. The third research question in this study sought to explore the purposes of why instructors used digital tools. Instructors mentioned in semi-structured interviews that they used social media tools widely in their personal and professional lives for several purposes, including communication, fun and pleasure, academic, and language learning purposes. They also stated that they could use digital tools in their teaching either as materials to enhance input and skills development or as tools to facilitate motivation, autonomy, creativity, group work, and engagement.

Based on EFL and IT instructors voice and Spires and Bartlett (2012) digital literacy taxonomy, the researchers proposed a Digital Literacy Curriculum that has seven components as Technical Skills, Civic Skills, Communicative Skills, Collaborating Skills, Computational thinking Skills, Investigating Skills and productive Skills (Figure.3).

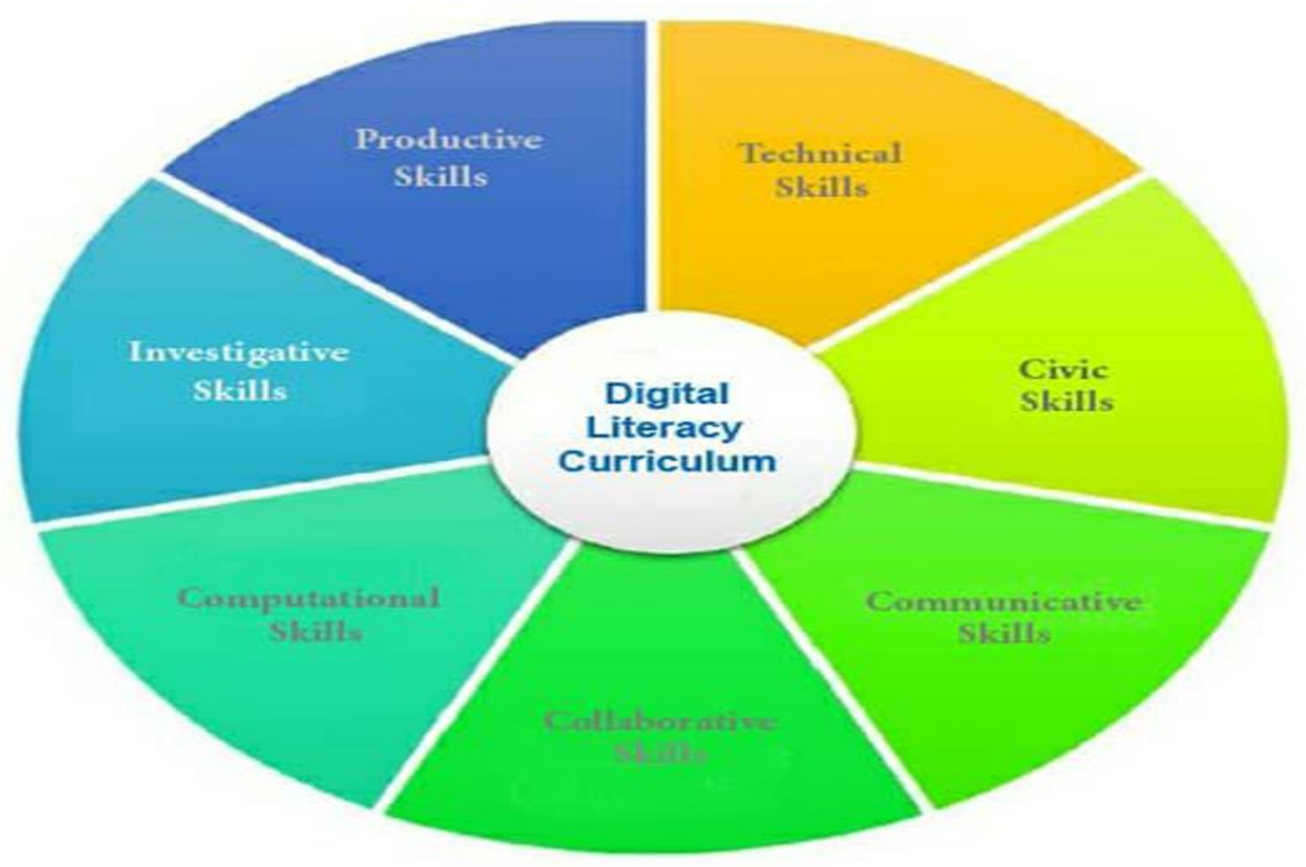

Figure 3. Digital Literacy curriculum components framework (Author, et al., 2021) based on Spires and Bartlett (2012) digital literacy taxonomy

This framework includes seven components as:

Technical Skills: Applying digital tools.

Civic Skills: Using digital tools in a best way.

Communicative Skills: Using digital communication protocols for sharing idea in a best way.

Collaborative Skills: Applying suitable digital platforms and tools to producing, evaluating and sharing digital contents.

Computational Thinking Skills: Applying critical thinking skills by digital tools for gathering, analyzing of data and information. 
Investigative Skills: Digital resources searching, identifying and validating.

Productive Skills: using digital tools for producing contents.

\section{Conclusion and recommendations}

Along with the digital world's speedy development and technology, instructors should be knowledgeable about integrating the best digital tools and evaluating them to be more effective. In some cases, instructors should be knowledgeable enough to modify existing digital content for their own context, which begins during initial teacher education and continues through continued professional development. The researchers explored instructors' voice about digital literacy curriculum components in the present study. This included an exploration of how instructors defined these components, what kind of tools they used and for which purposes they preferred to use digital tools. By doing so, the researchers identified instructors' voice on their digital literacy levels. Our findings indicated that instructors were aware of many digital tools and they perceived themselves to be competent enough to use these digital tools for personal, educational, and professional purposes. Their concept of digital literacy curriculum components seemed to made of different knowledge levels about digital tools usage in a critical, creative and collaborative way. While we focused solely on instructor's conceptualization of digital literacy curriculum components and their perceived use of digital tools, future research can employ observations of actual use or activities in which instructors can be presented with a problem to be solved using digital tools. This could provide a more comprehensive insight into instructors' digital literacy levels. Another area for future research involves instructors use of social media for professional development. Although some instructors acknowledged social media as a platform for professional development, they would definitely benefit from further guidance in using social media platforms in a variety of ways to become more competent in their profession.

The present study sheds light on the instructor's digital literacy level in Iran. However, when followed by further studies in other countries, it might contribute to the emergence of a comparative framework that allows for generalizations. It would be beneficial to look at this issue from a broader perspective to explore to what extent the definitions of digital literacy curriculum components differ from each other; what commonalities or differences exist regarding digital literacy skills of instructors, and the types and purposes of digital tools they are using; and whether it is ever possible to reach a common and shared understanding of both the definition and components of digital literacy curriculum components that would inform educational policymakers and instructors. Through examining such questions, future studies might also contribute to the establishment of a framework for the measurement of digital literacy skills for instructors.

\section{References}

[1] Akayoğlu, S., Satar, M., Dikilitaş, K., Cirit, N. C., \& Korkmazgil, S. (2020). Digital literacy practices of Turkish pre-service EFL teachers. Australasian Journal of Educational Technology, 36(1), 85-97. https://doi.org/10.14742/ajet.4711

[2] Covello, S. (2010). A review of digital literacy assessment instruments. Retrieved from http://idmodule.com/research-on-digitalliteracy-assessment-instruments-fulltext/

[3] Darling-Hammond, L. (2010). Performance counts: Assessment systems that support high-quality learning. Washington, DC: Council of Chief State School Officers. Retrieved from http://www.ccsso.org/Documents/2010/

Performance_Counts_Assessment_Systems_2010.pdf

[4] Dudeney, G., \& Hockly, N. (2016). Literacies, technology and language teaching. In F. Farr, \& L. Murray (Eds.). The Routledge handbook of language learning and technology. London: Routledge.

[5] Gianfranco, F., (2020). Digital literacy and the national curriculum for England: Learning from how the experts engage with and evaluate online content. Computers \& Education 152 (2020) 103859. Available: https://www.sciencedirect.com/science/article/pii/S0360131520300592

[6] Guest, G., MacQueen, K. M., \& Namey, E. (2012). Applied thematic analysis. Thousand Oaks, CA: Sage.

[7] Gilster, P. (1997). Digital literacy. New York, NY: Wiley.

[8] Hiller A. S. \& Melissa, E. B. (2012). Digital Literacies and Learning: Designing a Path Forward. Friday Institute White Paper Series. Retrieved from www.fi.ncsu.edu/whitepapers

[9] Hobbs, R. (2007). Reading the media: Media literacy in high school English. New York, NY: Teachers College Press

[10] Hague, C. \& Payton, S. (2010). Digital Literacy Across the Curriculum. Bristol, United Kingdom: Futurelab

[11] Hsu, S. (2010). Developing a scale for teacher integration of information and communication technology in grades 1-9. Journal of Computer Assisted Learning, 26(3), 175-189. https://doi.org/10.1111/j.1365-2729.2010.00348.x

[12] Janssen, J., Stoyanov, S., Ferrari, A., Punie, Y., Pannekeet, K., \& Sloep, P. (2013). Experts' views on digital competence: Commonalities and differences. Computers \& Education, 68(1), 473-481. https://doi.org/10.1016/j.compedu.2013.06.008

[13] Jamie, H., (2020). Digital Literacy \& the Adult Learner. Retrieved https://www.mcael.org/sites/default/files/digital literacy and the adult learner mcael.pdf

[14] Jisc. (2014). Developing digital literacies. Retrieved January 20, 2017, Available online:https://www.jisc.ac.uk/fullguide/developing-digital-literacies

[15] Kress, G. (2003). Literacy in the new media age. London, England: Routledge. 
[16] Lankshear, C., \& Knobel, M. (2008). Introduction. In C. Lankshear, \& M. Knobel. (Eds.). Digital literacies: Concepts, policies and practices (pp.1-16). New York, NY: Peter Lang. Retrieved from https://researchonline.jcu.edu.au/27788/1/27788_Lankshear_and_Knobel_2008.pdf

[17] Levin, B. (2008). Curriculum policy and the politics of what should be learned in schools. In M. F. Connelly (Ed.), The Sage handbook of curriculum and instruction (pp.7-24). Thousand Oaks, CA: Sage.

[18] McDougall, J., \& Livingstone, S. (2014). Media and information literacy policies in the UK. London, England: London School of Economics and Political Science. Retrieved from https://eprints.Ise.ac.uk/57103/.

[19] Odede, Israel R. and Jiyane, G. (2019) Exploring Dimensional Constructs of Digital Literacy Skill for Higher Education" (2019). Library Philosophy and Practice (e-journal). 2806. https://digitalcommons.unl.edu/libphilprac/2806

[20] Peled, Y. (2020). Pre-service teacher's self-perception of digital literacy: The case of Israel. Education and Information Technologies, 118.

[21] Prensky, M. (2001). Digital natives, digital immigrants. On the Horizon, 9(5), 1-6 https://doi.org/10.1108/10748120110424843

[22] Spires, H., \& Bartlett, M. (2012). Digital literacies and learning: Designing a path forward. Friday Institute White Paper Series. NC State University.

[23] Spires, H., Wiebe, E., Young, C., Hollebrands, K., \& Lee, J. (2009). Toward a new learning ecology: Teaching and learning in 1:1 learning environments. Friday Institute White Paper Series. NC State University: Raleigh, NC.

[24] Tang, C. M., \& Chaw, L. Y. (2016). Digital literacy: A prerequisite for effective learning in a blended learning environment? The Electronic Journal of e-Learning, 14(1), 54-65. Retrieved from https://www.ejel.org/issue/download.html?idArticle=485

[25] Thorne, S. L. (2013). Digital literacies. In M. R. Hawkins (Ed.), Framing languages and literacies: Socially situated views and perspectives. (pp. 192-218). New York, NY: Routledge. Retrieved from https://www.researchgate.net/publication/237191470 Thorne S L 2013 Digital Literacies In M Hawkins ed Framing Languages and Literacies Socially Situated Views and Perspectives pp 192-218 New York Routledge

[26] Trilling, B., \& Fadel, C. (2009). 21st Century Skills: Learning for Life in Our Times. A Francisco: Jossey-Bass.

[27] Tyger, R. L. (2011). Teacher candidates' digital literacy and their technology integration efficacy. (Doctoral dissertation). Georgia Southern University, Statesboro, GA. Retrieved from https://digitalcommons.georgiasouthern.edu/cgi/viewcontent.cgi?article=1557\&context=etd

[28] UNESCO (2018). A Global Framework of Reference on Digital Literacy Skills for Indicator 4.4.2. Available at http://www.uis.unesco.org

[29] Wallis, R., \& Buckingham, D. (2019). Media literacy: The UK's undead cultural policy. International Journal of Cultural Policy, 25(2), 188203. https://doi.org/10.1080/10286632.2016.1229314.

[30] White, D., \& Le Cornu, A. (2011). Visitors and Residents: A new typology for online engagement. First Monday, 16(9). https://doi.org/10.5210/fm.v16i9.3171 